\title{
Therapeutic Potential of Traditional Indian Herbal Medicine in COVID-19: A Narrative Review
}

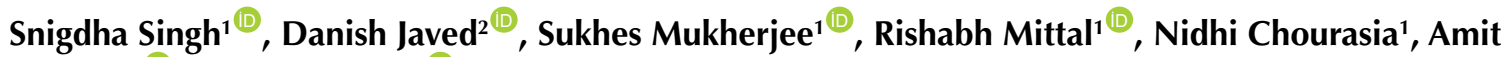 \\ Agrawal $^{(\oplus)}$, Ashwin Kotnis ${ }^{* * \mathbb{C}}$
}

1Department of Biochemistry, All India Institute of Medical Sciences (AIIMS), Bhopal, India

${ }^{2}$ Department of Ayurveda, Yoga \& Naturopathy, Unani, Siddha and Homoeopathy (AYUSH), All India Institute of

Medical Sciences (AIIMS), Bhopal, India

${ }^{3}$ Department of Neurosurgery, All India Institute of Medical Sciences (AIIMS), Bhopal, India

*Corresponding Author: Ashwin Kotnis, Ph.D., Associate Professor, Department of Biochemistry, All India Institute of Medical Sciences (AIIMS), Bhopal, India. Tel: +91-7773000869, Email: ashwin.biochemistry@aiimsbhopal.edu.in

Received February 12, 2021; Accepted May 22, 2021; Online Published May 30, 2021

\begin{abstract}
Background: Coronavirus disease 2019 (COVID-19) has become a global challenge to the health care system. A novel agent to combat this deadly virus is still a matter of research. Herbal molecules have served humanity since the beginning.

Objectives: This narrative review aims to study the antiviral properties of medicinal plants, which are already effectively used in the past against various viruses. It derives the importance of exploration of such phytochemicals, which can be complementarily used to treat COVID-19.

Methods: Studies related to traditional medicine and treatment for viruses were retrieved from databases including PubMed, Google scholar until December 2020 using the keywords SARS-CoV-2, COVID-19, Immunological, Phyto-chemicals, Traditional Medicine. The resulting publications were analyzed to develop a narrative review on the traditional Indian phytochemicals that have been shown to effectively treat various viral infections and potentially treat or prevent COVID-19.

Results: Many of the researches are showing that Indian herbal compounds have a significant potential against viral diseases. Plants like Azadirachta indica, Withania somnifera, Tinospora cordifolia, Ocimum basilicum, and many more have been shown tremendous antiviral, anti-inflammatory, and immune-modulatory activities.

Conclusion: Phytochemicals obtained from the herbs can be helpful in the treatment and prevention of SARS-CoV-2via various modes such as inhibition of attachment, penetration, uncoating, replication, assembly, and release of respiratory viruses. Further analysis of the potential phytochemicals in treating SARS-CoV-2 in clinical trials is warranted.

Keywords: SARS-CoV-2, COVID-19, Immunological, Phyto-chemicals, Traditional Medicine
\end{abstract}

\section{Background}

The milieu of the human establishment has come under threat of a newly discovered SARS-CoV-2 virus causing a disease called COVID-19 as designated by the World Health Organization (WHO) on February 11, 2020. ${ }^{1}$ This new era in the history of pandemics of infectious diseases began in Wuhan city, the capital of Hubei province in China, in December 2019. ${ }^{2,3}$ The prevailing conditions of the world have forced the WHO to declare the Pandemic., ${ }^{2,4}$ The havoc of severe acute respiratory syndrome coronavirus 2 (SARS-CoV-2) has enrolled around 220 nations of the world, infecting 72646646 individuals diseased and 1618908 deaths as of December 14, 2020. There are 9885100 confirmed cases in India, out of which 350918 are active cases, 9388239 are recovered, and 143393 deceased as of December 14, 2020. SARS-CoV-2 virus belongs to the genera of betacoronavirus of subfamily Orthocoronavirinae under the family of Coronaviridae., The virus causes multiorgan injury and disturbs the immunological balance leading to cytokine syndrome, which further adds to multiorgan failure. In this critical situation, herbal medicine can act as immunomodulatory agents in preventing and alleviating symptoms of COVID-19. This review discusses the potential herbal medicine that can restore immune homeostasis in COVID-19 patients by offering multi-target effects.

\section{Objectives}

This review focuses on understanding the pathogenesis of COVID-19, which allows exploring the various modes in which phytochemicals can be implemented to treat this infection. Hence, it is important to have a good collection of traditional medicinal plants known for their antiviral and anti-inflammatory actions against various other viruses like HIV, dengue, herpes etc. The review aims to explore some easily affordable natural products for the cure of the infection.

Copyright (C) 2021 The Author(s). This is an open-access article distributed under the terms of the Creative Commons Attribution License (http:// creativecommons.org/licenses/by/4.0), which permits unrestricted use, distribution, and reproduction in any medium, provided the original work is properly cited. 


\section{Methods}

The narrative review was conducted through major electronic bio-medical databases such as PubMed/ MEDLINE, Google Scholar, and Cochrane Database of Systematic Reviews. A comprehensive search of the articles published since inception to 01/12/2020 on COVID-19 and herbal medicine was carried out. Various search terms were used for databases as (("sars cov2"[All Fields]) OR ("covid 19”[All Fields])) AND ((“"management”[All Fields]) OR ("pathophysiology"[All Fields])) OR ("psychological”[All Fields])); present as "abstract", "Clinical trial” or "Metaanalysis" of last one year ; and ((“"sars cov2"[All Fields]) OR ("covid 19"[All Fields])) AND ("herbal medicine"[All Fields])) AND ((“"anti-inflammatory”[All Fields]) OR ("antiviral"[All Fields])) OR ("immunomodulatory"[All Fields])) since inception to $01 / 12 / 2020$. A total of 162 records were identified by electronic database searches, of which 95 records were screened further. Among these, 40 irrelevant articles were excluded, and 55 records were eligible for further consideration. In this study, biomedical articles were considered appropriate if they met the following inclusion criteria described: (1) COVID-19 pathophysiology, (2) management of COVID-19 patients, (3) findings of anti-inflammatory, antiviral and immunemodulatory properties for plants; and (4) full-text articles written in English. Studies that did not meet the inclusion criteria were excluded. Attention was given to prevent duplication of the studies. All the literature, irrespective of study design, was included in this paper. In this narrative review, 24 Indian herbs are selected for their antiviral and immunomodulatory actions after analyzing 55 articles.

\subsection{Analysis}

\subsubsection{Pathogenesis of COVID-19}

SARS-CoV-2 is a highly contagious virus. One of the reasons can be the presence of an enzyme, furin, in the host cell, which is important for the viral entry as its role is absent in other SARS-CoV. ${ }^{7}$ The Angiotensin-converting enzyme 2 (ACE2) receptor is responsible for the internalization of the virus, and TMPRSS2 serine proteases are utilized for the S-protein priming. ${ }^{8}$ The virus replicates by reverse transcription.

The body responds to the viral infection by presenting the viral antigenic peptides through antigen-presenting cells complexed with MHC class I and class II molecules to $\mathrm{CD}^{+}$ and $\mathrm{CD} 4^{+} \mathrm{T}$ cells. Different dendritic cells express a wide variety of C-type lectin and toll-like receptors to recognize conserved pathogen patterns and further immune response. The binding of ligands triggers the downstream signaling pathways responsible for cytokine release to Toll-like receptor. ${ }^{9}$ The adaptive immune responses are triggered by the migration of dendritic cells from peripheral tissues to the lymph node. Respiratory viral infections such as SARSCoV-2 affect immune homeostasis by altering the immune regulatory network leading to decreased responsiveness, changes in lymphocyte subpopulations, and decreased macrophage function. Clinically, the immune response induced by SARS-CoV-2 infection occurs in two phases: the first immune defense-based protective phase and the second inflammation-driven damaging phase. The first immune defense-based protective phase is characterized by recruitment of antibody-secreting cells, follicular helper T-cells, activated CD4 and CD8 T-cells, immunoglobulin M (IgM), and immunoglobulin G (IgG) antibodies that bind to SARS-CoV-2. The second phase leads to uncontrolled cytokine release causing cytokine release syndrome (CRS), or 'cytokine storm' characterized by increased interleukin-2 (IL-2), IL-7, granulocyte colonystimulating factor, interferon gamma (IFN- $\gamma$ ) and tumour necrosis factor alpha (TNF- $\alpha$ ). Respiratory viruses like SARS-CoV-2 usually induce inflammatory chemokines such as macrophage inflammatory protein (MIP)-1a/ CXCL ten and monocyte chemotactic protein (MCP)-1/ CCL2.

The SARS-CoV encodes several structural and nonstructural proteins like nsp1, nsp3-macrodomain, nsp3deubiquitinase, ORF3b, ORF6, and ORF9b to overcome the human immune response. ${ }^{10}$ They subvert IFN- $\Upsilon$ signaling by blocking STAT1 phosphorylation and inhibiting TBK1/ IKKe. ${ }^{10}$ The robust viral replication leads to suboptimal T-cell and antibody response, antagonized and delayed IFN response leading to amplified dysregulated inflammatory responses. The delayed IFN- $\alpha / \beta$ response is accompanied by the accumulation of pathogenic inflammatory monocyte-macrophages (IMM), resulting in increased levels of monocytes, chemoattractants such as CCL2, CCL7, and CCL12 through IFN- $\alpha / \beta$ receptor stimulation which further increases the count of IMMs and hence enhances the disease severity. ${ }^{10}$ There is a production of elevated levels of proinflammatory cytokines such as TNF, IL-6, IL-1 $\beta$, and inducible NO synthase (iNOS) by these IMMs, contributing to acute respiratory distress syndrome (ARDS). Thus, SARS-CoV infection, high virus titers, and cytokine/chemokine response dysregulation cause an inflammatory cytokine storm. CRS damages tissues of the lungs, kidney, and heart leading to rapid multiorgan failure. The deaths from COVID-19 are due to massive alveolar damage leading to ARDS that culminates in respiratory failure. Restoration of Th1/Th-2 cytokine balance is one of the mechanisms of establishing immune homeostasis. Scientific evidence based on research spanning over 25 years indicates that Ayurveda Rasayana, such as Ashwagandha (Withania somnifera L. Dunal; WS), can be a potential candidate for management COVID-19.

\subsubsection{Clinical Classification}

The signs and symptoms leading to the clinical presentation of COVID-19 include fever (83\%-99\%), cough (59\%-82\%), fatigue $(44 \%-70 \%)$, anorexia $(31 \%-40 \%)$, shortness of breath (11\%-35\%). The patient can also suffer from other non-specific symptoms like sore throat, nasal congestion, headache, diarrhea, nausea and vomiting, anosmia, and ageusia. ${ }^{11}$ 


\subsubsection{Clinical Management of COVID-19}

The recent outbreak of COVID-19 is being managed by measures aiming to prevent the transmission of the disease and supportive care. WHO, European Respiratory Society, CDC, ESC guidance, several country-specific and international guidelines ranging from prevention to management of severe COVID-19 cases are currently present and regularly revised with research and analysis. The Indian National Task Force for COVID-19, constituted by the Indian Council of Medical Research (ICMR), has recommended using hydroxychloroquine as a prophylactic drug for high-risk populations on March 22, 2020.12 A multinational Phase III-IV clinical trial, called "SOLIDARITY TRIAL for treatment," announced on March 18, 2020 by WHO intends the efficacy and potency of existing antiviral and anti-inflammatory drugs in hospitalized COVID-19 patients. ${ }^{13}$ In May 2020, WHO has announced a "SOLIDARITY TRIAL for vaccines" to develop a multinational coalition of vaccine scientists defining a global target product profile for COVID-19. The treatment candidates include local standard care plus $(a)$ remdesivir alone, (b) lopinavir and ritonavir combined, (c) lopinavir/ritonavir combined with interferon- $\beta$ and (d) hydroxychloroquine or chloroquine. ${ }^{14}$ Hydroxychloroquine now does not stand as a valuable candidate.

\subsubsection{Present Treatment Therapy}

a) Hydroxychloroquine and chloroquine: Mechanism of action: They prevent the transport, entry, and inhibit the post-entry stages of SARS-CoV-2. They interfere with the glycosylation of the cellular receptor of SARS-CoV2 and thus prevent the entry of the virus. They also inhibit MAP- kinase and thus interfere with the SARS-CoV2 molecular recognition.

$\beta)$ Lopinavir-ritonavir \& Interferon $\beta$-1a: Mechanism of action: It acts by inhibiting the post-translational modification of viral proteins.

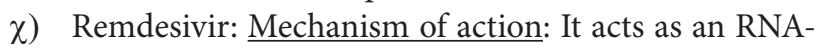
dependent RNA polymerase inhibitor and brings about premature termination of RNA transcription.

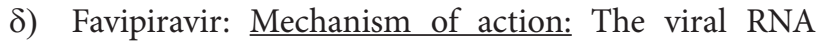
polymerase complex is rapidly mutated by the action of Favipiravir, resulting in a large proportion of nonviable viruses within the total virus population.

ع) Corticosteroids: They are considered a potential tool in treating COVID-19 patients as they reduce inflammation and fibrosis.

ф) Convalescent plasma: Mechanism of action: The logic behind using convalescent plasma is that the patient recovering from COVID-19 will have immunoglobulin antibodies in their plasma, suppressing the viremia in the present patient.

\section{Results}

4.1. Potential Phytochemicals for COVID-19Management WHO promotes the use of scientifically proven traditional medicine and works with research institutions to sort out and optimize traditional medicinal products that can be investigated for clinical efficacy and safety for COVID-19 treatment. In India, the clinical research on establishing protocols for using Ayurvedic medicines as complementary or preventive measures in treating SARS-CoV-2 infection is emerging. It will attain an edge as there is approval from the Ministries of AYUSH, Health, Science and Technology, Council of Scientific and Industrial Research (CSIR,) and technical support of ICMR to launch studies in this field. The phytochemical which can be utilized for prevention and treatment of COVID-19 are described in Table 1.

Azadirachta indica_is a valuable, versatile tree distributed all over India. Aqueous extract of bark of A. indica (Neem) has shown its antiviral action against Herpes simplex virus-1 by acting as a potent entry inhibitor. The glycoprotein of HSV-1 brings about the polykaryocytes formation via cell to cell fusion. The extract of bark from this plant inhibited this process. ${ }^{15}$ Cytotoxicity was not shown even at the higher concentration, and inhibition against poliovirus was found significant by inhibiting the initial stage of viral replication. ${ }^{16}$

Andrographis paniculata is a native plant of South Asian countries. The alcoholic extract of $A$. paniculata or Kalmegh plant treated against DENV 1-4-infected Vero cells have shown viral load inhibition by reverse transcription polymerase chain reaction (RT-PCR) analysis resulted as $75 \%$ of dengue viral inhibition. ${ }^{17}$ The actual compounds responsible for the antiviral activity are 14-deoxy-11,12-didehydroandrographolide and andrographolide. ${ }^{18}$ In a recent in-silico study in the context of SARS-CoV-2, andrographolide was found to be the main protease inhibitor of corona virus. ${ }^{19}$ In another study, viral growth and replication inhibition was more prompt with the methanolic extracts of $A$. paniculata tested against Vero E6 cells than five other herbs. ${ }^{20}$

Tinospora cordifolia (Guduchi or Giloy) is an herb found in high altitudes of tropical regions of the Indian subcontinent. It was observed that the stem extract of $\mathrm{T}$. cordifolia inhibited the growth of HSV-1 by up to $61.43 \%$ demonstrating virucidal activity. ${ }^{21}$ In this study, immune stimulation by activating various subsets of lymphocytes such as B-cells, T-cells, Natural killer cells was shown by a polysaccharide extracted from T. cordifolia at $100 \mu \mathrm{g} /$ $\mathrm{mL}$ concentration. Experiments demonstrate that the Th1 pathway of T helper cells with a self-regulatory mechanism is responsible for controlling cytokine production. ${ }^{22}$ The pathogen-free chicks were experimentally infected with a very virulent IBDV, and then they were treated with an aqueous extract of $T$. cordifolia. It has shown a significant increase in the IFN- $\gamma$, IL-4, IL-1 and IL-2 levels in the peripheral blood mononuclear cells of these chickens. ${ }^{23,24}$

Piper longum is also known for its immunomodulatory responses. Balb/c mice were administered with the extract of $P$. longum and piperine, which resulted in increased a-esterase positive cells, bone marrow cellularity, and the total WBC count to 142.8 and $138.9 \%{ }^{25}$

Withaferin $\mathrm{A}$, an active compound of Withania 


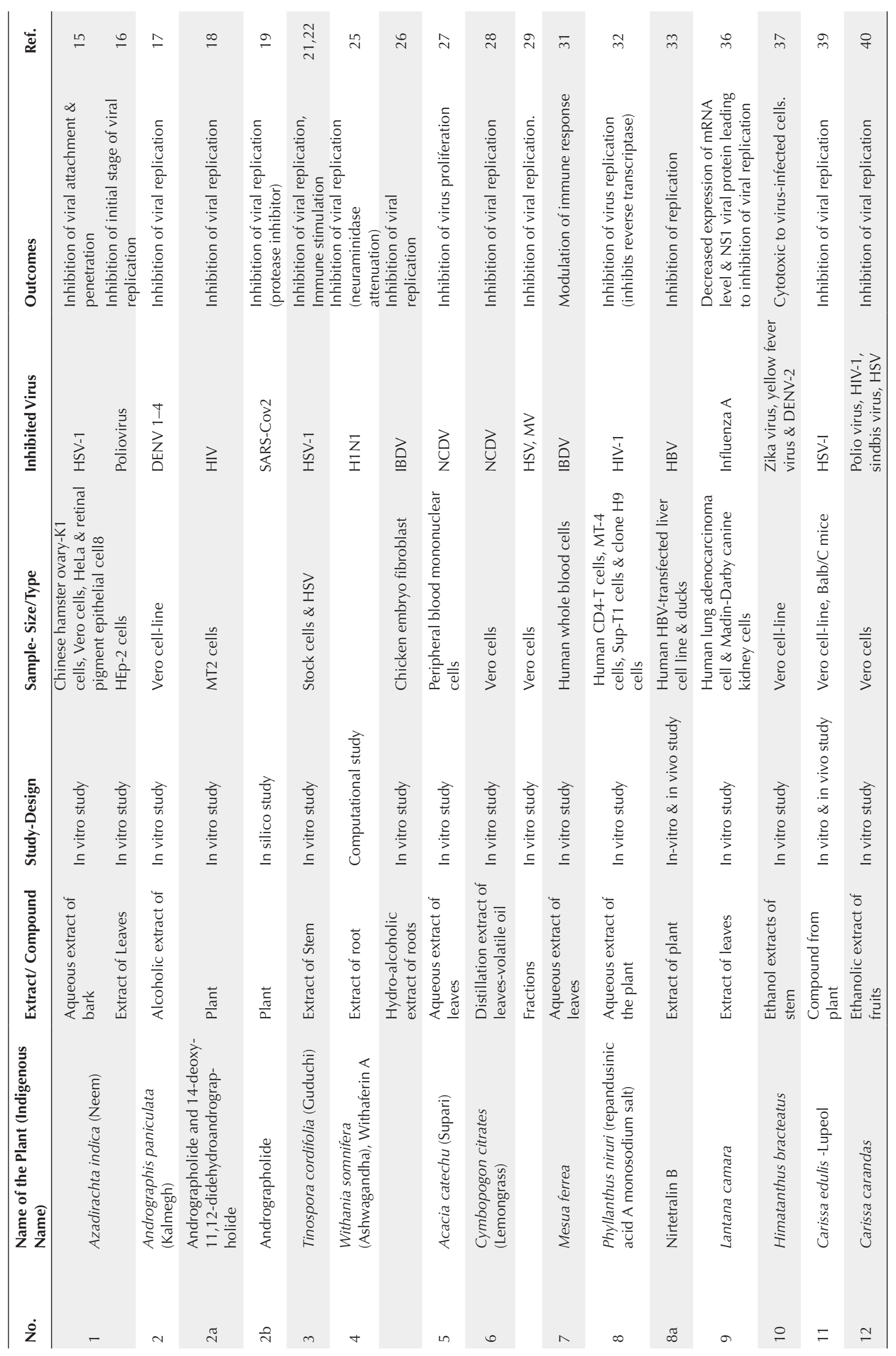




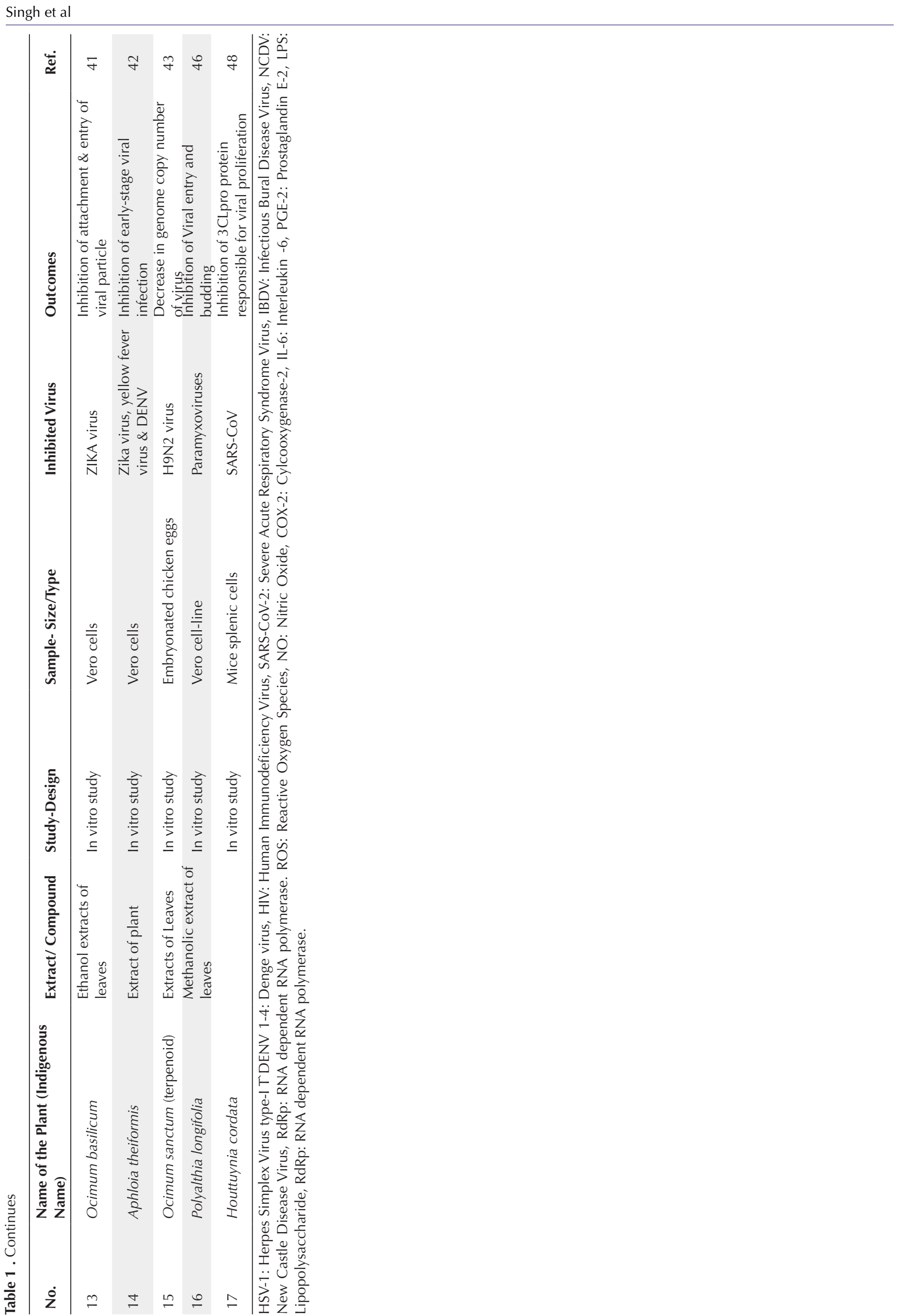


somnifera had shown a significant potential to weaken the neuraminidase of H1N1 influenza in a docking study. ${ }^{26}$ The infectious bursal disease virus was inhibited by hydroalcoholic extract of $W$. somnifera roots at a maximum of $99.9 \%$ in its highest nontoxic concentration. ${ }^{27}$

The infected human peripheral blood mononuclear cells with New Castle Disease Virus were treated with an aqueous extract of leaves of Acacia catechu. It was found that the extract caused inhibition of virus proliferation and also turned down CD14 monocyte surface marker. ${ }^{28}$

The nano gel obtained from Cymbopogon citrates strongly inhibited the Herpes simplex virus in a non-cytotoxic concentration. ${ }^{29}$ The entry of viruses into cells was found to be prevented by different fractions of Cymbopogon, obtained with the help of chromatography. ${ }^{30}$

Active compounds of Mimusops elengi, such as gallocatechin and epigallocatechin, have shown strong antiHIV-1 integrase enzyme activity. ${ }^{31}$ In order to determine the antigen (IBD, infectious bursal disease virus) specific immune response, including CD14 monocyte surface marker, the aqueous leaves extract of Mimusops elengi, and Mesua ferrea were tested on lysed whole blood of human and a decline in a dose-dependent manner in antigenspecific immune response was observed. ${ }^{32}$

The active molecule repandusinic acid obtained from Phyllanthus niruri was found to inhibit the human immunodeficiency virus type-1 reverse transcriptase (HIV-1-RT) enzyme and HIV-1-induced giant cell formation. ${ }^{33}$ Nirtetralin B obtained from P. niruri was an effective antiviral agent against duck hepatitis $B$ virusinfected ducks and human HBV-transfected liver cell line HepG2.2.15. ${ }^{34}$

Silver nano-particles from A. paniculata, T. cordifolia, and $P$. niruri_were evaluated for their antiviral properties against chikungunya virus and found effective in decreasing order respectively. ${ }^{35,36}$

The leaves extract of _Lantana camara was found to restrict viral replication when evaluated against replicating influenza A virus on A549, MDCK II cell lines, and on some cytokines IFN $\beta$ and IRF3 and viral protein expression like NS1 protein. ${ }^{37}$ However, the leaf extract failed to protect the cell cultures with a high polio type 1 virus challenge.

The ethanolic extracts of the stem of Himatanthus bracteatus expressed good antiviral activity against dengue virus-2, yellow fever virus, and Zika virus and for cytotoxicity in Vero cells. The fraction of plumeria molecule was found active only against Zika virus. ${ }^{38}$

Lupeol isolated from Carissa edulis has shown significant viricidal activity against Herpes simplex virus types- 1 by reducing viral yields in Vero E6 cells. ${ }^{39}$ Potent antiviral activity against $\mathrm{HIV}-1$ at $6 \mu \mathrm{g} / \mathrm{mL}$, sindbis virus at $3 \mu \mathrm{g} /$ $\mathrm{mL}$, poliovirus, and herpes simplex virus at $12 \mu \mathrm{g} / \mathrm{mL}$ was shown by the ethanolic extract of Carissa carandas fruits. ${ }^{40}$

Sweet basil, known as Ocimum basilicum, is a very wellknown medicinal herb. Zika virus replication in Vero E6 cells is efficiently inhibited by basil leaves ethanolic extract. This inhibitory action is assumed at the pace of attachment and entry into the host cell. ${ }^{41}$

In another study of the ZIKA virus, Aphloia theiformis impairs the viral attachment to the cell surface and inhibits virus entry in host cells. ${ }^{42}$

Ocimum sanctum (Tulsi) leave extract has shown promising antiviral properties against avian influenza $\mathrm{H} 9 \mathrm{~N} 2$ virus. ${ }^{43} \mathrm{H} 1 \mathrm{~N} 1$ infected MDCK cells were treated with the ethanolic extract of $O$. sanctum and highly effective in post-treatment mode. ${ }^{44}$ In a trial, three hundred milligrams capsules of ethanolic extracts of leaves of Tulsi empty stomach showed immunomodulatory effects by the significant increase in the levels of interferon- $\gamma$ and interleukin-4 levels proportion of T-helper and T-cytotoxic cells and NK-cells. ${ }^{45}$

In an in vitro study, methanolic extract of Polyalthia longifolia leaves has shown antiviral action at paramyxoviral entry and budding. ${ }^{46}$ Catechins obtained from this plant have also shown antiviral action by blocking viral entry or directly inhibiting the viral particles.

In one of the recent in-silico studies to explore potential COVID-19 inhibitors among phytochemicals, aqueous solubility, lipophilicity, and binding affinity of Nyctanthes arbortristis (Harsingar) were observed. N. arbortristis (Harsingar) is found to have the highest inhibition potentials among the 11 species. ${ }^{47}$

Studies have suggested that water extract of Houttuynia cordata has increased the proportion of CD4+ and CD8+ $\mathrm{T}$ cells and significantly increase the secretion of IL2 and IL-10. RNA-dependent RNA polymerase (RdRp) and SARS-CoV 3C-like protease (3CLpro) extract Houttuynia cordata $^{48}$ show inhibitory action.

The seeds, roots, and leaves of Vitex negundo yield several bioactive compounds in flavonoids, volatile oils, iridoids, lignans, terpenes, and steroids. These bioactive compounds exhibit anti-oxidant, anti-inflammatory, antidiabetic, anticancer, and antimicrobial properties. The recruitment of neutrophils and activation of macrophages can be regulated by vitexin, flavonoids. In lipopolysaccharide challenged mice, the release of $\mathrm{NO}$, IL- $1 \beta$, and TNF- $\alpha$ in their peritoneal cavity is reduced. The reduction in the expression of $\mathrm{p}$-JNK, $\mathrm{p}$-ERK1/2, and p-p38, in LPS-elicited cells and the regulation of expression of transcriptional factors for proinflammatory mediators is brought about by vitexin. ${ }^{49}$ Anti-inflammatory action is shown by lignin found in V. negundo (Nirgundi). The leaf oil of $V$. negundo can bring about the inhibition of the cyclooxygenase 2 (COX-2) pathway without interference with COX-1 pathways. The treatment with casting reduces the levels of chemokines and proinflammatory cytokines in the bronchoalveolar lavage fluid due to the inhibition of lymphocytes, macrophages, and neutrophils. ${ }^{50}$

The use of Vitex rotundifolia fruits (Casticin) can inhibit PGE2 and nitric oxide, reducing the level of tumor necrosis factor a (TNF-a) IL-6 and thus, induction of apoptosis. This compound, casting, is also responsible for suppressing the expression of COX-2 and iNOS and increasing the production of Nrf2 and HO-1. Furthermore, significant 
inhibition of NF- $\mathrm{BB}$ (nuclear factor kappa B) subunit p65 proteins in the nucleus and reduction inactivation of Akt and MAPK is observed by the application of casticin. ${ }^{51}$

Vaccine, obtained from Adhatoda vasica, shows bronchodilation by acting on their particular respiratory sensors and peripheral receptors. It is observed that there is an increase in the titer of serum antibody and the number of spleen plasma cells with a simultaneous reduction in the immune response of delated type hypersensitivity, myeloperoxidase enzyme activity in the spleen, and IFN- $\gamma$, TNF- $\alpha$, and IL- 6 serum levels. ${ }^{52}$

A significant reduction in LPS induction of iNOS, COX2 , IL-6, and IL-1 $\beta$ expression was observed using naringin from citrus fruits $(40,20,10 \mu \mathrm{g} / \mathrm{mL})$. With potent binding sites at TYR-515, GLU-398, GLU-402 and ASN394, Naringin has shown the highest binding activity to the ACE2 enzyme with estimated docking energy of -6.85 $\mathrm{kcal} / \mathrm{mol}^{53}$

The downregulation of COX-2 gene expression and iNOS through inactivation of NF- $\kappa \mathrm{B}$, upregulation of histone $\mathrm{H} 3$ acetylation, and suppressed histone deacetylase (HDAC) 1 expression and inhibition of arachidonic acid-induced platelet aggregation and formation of thromboxane B can be regulated by the anti-inflammatory action of Zingiber officinale. It can also lead to the inhibition of TNF-a, IL-8, and IL-1. ${ }^{54}$

\section{Discussion}

COVID-19 has caused significant mortality and morbidity worldwide since December 2020. Several drugs and vaccines are being tested toward the treatment of COVID-19.

\section{Research Highlights}

\section{What Is Already Known?}

- There is a worldwide search to treat the pandemic of COVID-19 caused by the SARS-CoV-2 virus that has affected millions globally.

- Currently, available drugs for the treatment of COVID-19 have limitations in completely curing the disease, availability, and cost.

- Indian medical herbs have been traditionally using for treating ailments and have the potential to treat viral diseases.

\section{What Does This Study Add?}

- This narrative review describes 24 traditional Indian herbs that inhibit replication and propagation for viruses such as SCOV2, polio, influenza, HIV, HSV1 in cell line and animal models, etc.

- Phytochemicals Withania somnifera, Nyctanthes arbortristis, Houttuynia cordata warrant clinical trials to study the efficacy to target SARS-CoV-2.

- Herbal drugs can be repurposed for the treatment of SARS-COV-2, and they would be affordable, easily available to everyone with minimal adverse effects.
Many of these drugs, some of which are repurposed, are targeted for immunomodulation that will inhibit viral entry, blocking viral replication and translation, induction of antiviral immunity, virus clearance, anti-inflammatory effect, and no drug proven fully effective in curing the disease or preventing the infection. It has been reported that conventional drugs such as remdesivir, lopinavir, ritonavir, chloroquine, and hydroxychloroquine used for treating COVID-19 are not as effective as expected. ${ }^{55}$ Thus, newer drugs with minimal side effects are warranted for effective treatment of COVID-19. In such a scenario, repurposing phytochemicals with potent antiviral effects and promoting immune homeostasis can be beneficial. Here we describe phytochemicals used traditionally as herbal medicines and recommend testing their efficacy in treating COVID-19 using high quality and rigorously peerreviewed clinical trials. Amongst the 31 phytochemicals reviewed for antiviral and immunomodulatory activities, compounds obtained from Withania somnifera Nyctanthes arbortristis, Houttuynia cordata have been shown effective against SARS-CoV-2 by inhibiting viral proteases and the interaction site of viral S protein with host receptor ACE-2; Nyctanthes arbortristis has shown the highest lipophilicity, aqueous solubility and binding affinity for SARS CoV-2 and Houttuynia cordata by inhibiting viral replication by inhibition of 3CLpro protein and RdRp.

\section{Conclusion}

The idea of screening potential active components from traditional herbal medicine is a useful strategy and should be pursued. Hence research on phytochemicals would assist in developing dose-specific products for the treatment of COVID-19, which would be easily available, affordable, and shall have minimal adverse effects.

\section{Authors' Contributions}

All authors contributed equally to this study.

\section{Conflict of Interest Disclosures}

The authors declare that there is no conflict of interests.

\section{Ethical Approval}

Not applicable.

\section{References}

1. Naming the coronavirus disease (COVID-19) and the virus that causes it. https://www.who.int/emergencies/diseases/ novel-coronavirus-2019/technical-guidance/naming-thecoronavirus-disease-(covid-2019)-and-the-virus-thatcauses-it.

2. Li Y, Liu X, Guo L, et al. Traditional Chinese herbal medicine for treating novel coronavirus (COVID-19) pneumonia: protocol for a systematic review and meta-analysis. Syst Rev. 2020;9(1):75. doi:10.1186/s13643-020-01343-4.

3. Rothan HA, Byrareddy SN. The epidemiology and pathogenesis of coronavirus disease (COVID-19) outbreak. J Autoimmun. 2020;109:102433. doi:10.1016/j. jaut.2020.102433. 
4. Salvi R, Patankar P. Emerging pharmacotherapies for COVID-19. Biomed Pharmacother. 2020;128:110267. doi:10.1016/j.biopha.2020.110267.

5. Pedersen SF, Ho YC. SARS-CoV-2: a storm is raging. J Clin Invest. 2020;130(5):2202-2205. doi:10.1172/jci137647.

6. Ye Q, Wang B, Mao J. The pathogenesis and treatment of the 'Cytokine Storm' in COVID-19. J Infect. 2020;80(6):607613. doi:10.1016/j.jinf.2020.03.037.

7. Walls AC, Park YJ, Tortorici MA, Wall A, McGuire AT, Veesler D. Structure, function, and antigenicity of the SARSCoV-2 spike glycoprotein. Cell. 2020;181(2):281-292.e6. doi:10.1016/j.cell.2020.02.058.

8. Hoffmann M, Kleine-Weber H, Schroeder S, et al. SARSCoV-2 cell entry depends on ACE2 and TMPRSS2 and is blocked by a clinically proven protease inhibitor. Cell. 2020;181(2):271-280.e8. doi:10.1016/j.cell.2020.02.052.

9. Lau YL, Peiris JS, Law HK. Role of dendritic cells in SARS coronavirus infection. Hong Kong Med J. 2012;18 Suppl 3:28-30.

10. Channappanavar R, Perlman S. Pathogenic human coronavirus infections: causes and consequences of cytokine storm and immunopathology. Semin Immunopathol. 2017;39(5):529-539. doi:10.1007/s00281-017-0629-x.

11. Clinical management of COVID-19. https://www.who. int/publications-detail-redirect/clinical-management-ofcovid-19.

12. Meo SA, Klonoff DC, Akram J. Efficacy of chloroquine and hydroxychloroquine in the treatment of COVID-19. Eur Rev Med Pharmacol Sci. 2020;24(8):4539-4547. doi:10.26355/ eurrev_202004_21038.

13. UN Chief Renews Call For COVID-19 Solidarity as WHO Warns 'Majority' of World Still at Risk. CARICOM Today https://today.caricom.org/2020/05/19/un-chief-renewscall-for-covid-19-solidarity-as-who-warns-majority-ofworld-still-at-risk/. Published 2020.

14. "Solidarity" clinical trial for COVID-19 treatments. https://www.who.int/emergencies/diseases/novelcoronavirus-2019/global-research-on-novel-coronavirus2019-ncov/solidarity-clinical-trial-for-covid-19-treatments.

15. Tiwari V, Darmani NA, Yue BY, Shukla D. In vitro antiviral activity of neem (Azardirachta indica L.) bark extract against herpes simplex virus type-1 infection. Phytother Res. 2010;24(8):1132-1140. doi:10.1002/ptr.3085.

16. Faccin-Galhardi LC, Yamamoto KA, Ray S, Ray B, Carvalho Linhares RE, Nozawa C. The in vitro antiviral property of Azadirachta indica polysaccharides for poliovirus. J Ethnopharmacol. 2012;142(1):86-90. doi:10.1016/j. jep.2012.04.018.

17. Ramalingam S, Karupannan S, Padmanaban P, et al. Antidengue activity of Andrographis paniculata extracts and quantification of dengue viral inhibition by SYBR green reverse transcription polymerase chain reaction. Ayu. 2018;39(2):87-91. doi:10.4103/ayu.AYU_144_17.

18. Reddy VL, Reddy SM, Ravikanth V, et al. A new bisandrographolide ether from Andrographis paniculata nees and evaluation of anti-HIV activity. Nat Prod Res. 2005;19(3):223-230. doi:10.1080/14786410410001709197.

19. Enmozhi SK, Raja K, Sebastine I, Joseph J. Andrographolide as a potential inhibitor of SARS-CoV-2 main protease: an in silico approach. J Biomol Struct Dyn. 2021;39(9):3092-3098. doi:10.1080/07391102.2020.1760136.

20. Tang LI, Ling AP, Koh RY, Chye SM, Voon KG. Screening of anti-dengue activity in methanolic extracts of medicinal plants. BMC Complement Altern Med. 2012;12:3. doi:10.1186/1472-6882-12-3.

21. Pruthvish R, Gopinatha SM. Antiviral prospective of Tinospora cordifolia on HSV-1. Int J Curr Microbiol Appl Sci. 2018;7(1):3617-3624. doi:10.20546/ijcmas.2018.701.425.

22. Nair PK, Rodriguez S, Ramachandran R, et al. Immune stimulating properties of a novel polysaccharide from the medicinal plant Tinospora cordifolia. Int Immunopharmacol. 2004;4(13):1645-1659. doi:10.1016/j.intimp.2004.07.024.

23. Sachan S, Dhama K, Latheef SK, et al. Immunomodulatory Potential of Tinospora cordifolia and CpG ODN (TLR21 agonist) against the very virulent, infectious bursal disease virus in SPF chicks. Vaccines (Basel). 2019;7(3). doi:10.3390/ vaccines7030106.

24. Najmi A, Javed D, Ray A, Sadasivam B. Review of antiviral activities present in some Indian medicinal plants - Can they be used against SARS-CoV-2? Int Arch BioMed Clin Res. 2020;6(4):RA1-RA5. doi:10.21276/iabcr.2020.6.4.1.

25. Sunila ES, Kuttan G. Immunomodulatory and antitumor activity of Piper longum Linn. and piperine. J Ethnopharmacol. 2004;90(2-3):339-346. doi:10.1016/j. jep.2003.10.016.

26. Cai Z, Zhang G, Tang B, Liu Y, Fu X, Zhang X. Promising anti-influenza properties of active constituent of Withania somnifera ayurvedic herb in targeting neuraminidase of H1N1 influenza: computational study. Cell Biochem Biophys. 2015;72(3):727-739. doi:10.1007/s12013-0150524-9.

27. Pant M, Ambwani T, Umapathi V. Antiviral activity of Ashwagandha extract on infectious bursal disease virus replication. Indian J Sci Technol. 2012;5(5):2750-2751.

28. Gupta A, Chaphalkar SR. Cytotoxic and anti-viral activity of Acacia catechu on human peripheral blood mononuclear cells. Indones J Pharm. 2016;27(2):111-116.

29. Almeida KB, Araujo JL, Cavalcanti JF, et al. In vitro release and anti-herpetic activity of Cymbopogon citratus volatile oil-loaded nanogel. Rev Bras Farmacogn. 2018;28(4):495502. doi:10.1016/j.bjp.2018.05.007.

30. Nurul Aini MN, Said MI, Nazlina I, Hanina MN, Ahmad IB. Screening for antiviral activity of sweet lemon grass (Cymbopogon nardus (L.) Rendle) fractions. J Biol Sci. 2006;6(3):507-510. doi:10.3923/jbs.2006.507.510.

31. Suedee A, Tewtrakul S, Panichayupakaranant P. Anti-HIV-1 integrase activity of Mimusops elengi leaf extracts. Pharm Biol. 2014;52(1):58-61. doi:10.3109/13880209.2013.810649.

32. Gupta A, Chaphalkar SR. Inhibitory potential of aqueous leaves extract of Messua ferrea and Mimusops elengi on antigen specific immune response using human whole blood. Asian J Med Pharm Res. 2015;5(3):22-26.

33. Ogata $T$, Higuchi $H$, Mochida $S$, et al. HIV-1 reverse transcriptase inhibitor from Phyllanthus niruri. AIDS Res Hum Retroviruses. 1992;8(11):1937-1944. doi:10.1089/ aid.1992.8.1937.

34. Liu S, Wei W, Shi K, Cao X, Zhou M, Liu Z. In vitro and in vivo anti-hepatitis $B$ virus activities of the lignan niranthin isolated from Phyllanthus niruri L. J Ethnopharmacol. 2014;155(2):1061-1067. doi:10.1016/j.jep.2014.05.064.

35. Jantan I, Haque MA, Ilangkovan M, Arshad L. An insight into the modulatory effects and mechanisms of action of phyllanthus species and their bioactive metabolites on the immune system. Front Pharmacol. 2019;10:878. doi:10.3389/ 
fphar.2019.00878.

36. Sharma V, Kaushik S, Pandit P, Dhull D, Yadav JP, Kaushik S. Green synthesis of silver nanoparticles from medicinal plants and evaluation of their antiviral potential against chikungunya virus. Appl Microbiol Biotechnol. 2019;103(2):881-891. doi:10.1007/s00253-018-9488-1.

37. Hasan RN. Antiviral activity of leaves extract of lantana camara against the replication of A virus A/Puerto Rico/8/34(PR8). Al-Anbar J Vet Sci. 2017;10(1):1-8.

38. da Silva ML, Stehmann JR, Serafim MSM, et al. Himatanthus bracteatus stem extracts present anti-flavivirus activity while an isolated sesquiterpene glucoside present only anti-Zika virus activity in vitro. Nat Prod Res. 2019:1-5. doi:10.1080/1 4786419.2019.1690487.

39. Tolo FM, Rukunga GW, Muli FW, et al. The antiviral activity of compounds isolated from Kenyan Carissa edulis (Forssk.) Vahl. J Med Plants Res. 2010;4(15):1517-1522. doi:10.5897/ jmpr09.065.

40. Tesfaye T, Ravichadran Y. Traditional uses, pharmacological action and phytochemical analysis of Carissa carandas Linn.: a review. Nat Prod Chem Res. 2018;6(5):334. doi:10.4172/2329-6836.1000334.

41. Singh P, Chakraborty P, He DH, Mergia A. Extract prepared from the leaves of Ocimum basilicum inhibits the entry of Zika virus. Acta Virol. 2019;63(3):316-321. doi:10.4149/ av_2019_307.

42. Clain E, Sinigaglia L, Koishi AC, et al. Extract from Aphloia theiformis, an edible indigenous plant from Reunion Island, impairs Zika virus attachment to the host cell surface. Sci Rep. 2018;8(1):10856. doi:10.1038/s41598-018-29183-2.

43. Ghoke SS, Sood R, Kumar N, et al. Evaluation of antiviral activity of Ocimum sanctum and Acacia arabica leaves extracts against $\mathrm{H} 9 \mathrm{~N} 2$ virus using embryonated chicken egg model. BMC Complement Altern Med. 2018;18(1):174. doi:10.1186/s12906-018-2238-1.

44. Joshi G, Sharma S, Acharya J, Parida M. Assessment of in vitro antiviral activity of Ocimum sanctum (Tulsi) against pandemic swine flu H1N1 virus infection. World Res J Antimicrob Agents. 2014;3(1):62-67.

45. Mondal S, Varma S, Bamola VD, et al. Double-blinded randomized controlled trial for immunomodulatory effects of Tulsi (Ocimum sanctum Linn.) leaf extract on healthy volunteers. J Ethnopharmacol. 2011;136(3):452-456. doi:10.1016/j.jep.2011.05.012.

46. Yadav P, Choudhury S, Barua S, et al. Polyalthia longifolia leaves methanolic extract targets entry and budding of viruses-an in vitro experimental study against paramyxoviruses. J Ethnopharmacol. 2020;248:112279. doi:10.1016/j.jep.2019.112279.

47. Srivastava AK, Kumar A, Misra N. On the inhibition of COVID-19 protease by indian herbal plants: an in silico investigation. ArXiv. 2020.

48. Lau KM, Lee KM, Koon CM, et al. Immunomodulatory and anti-SARS activities of Houttuynia cordata. J Ethnopharmacol. 2008;118(1):79-85. doi:10.1016/j. jep.2008.03.018.

49. Rosa SI, Rios-Santos F, Balogun SO, Martins DT. Vitexin reduces neutrophil migration to inflammatory focus by down-regulating pro-inflammatory mediators via inhibition of p38, ERK1/2 and JNK pathway. Phytomedicine. 2016;23(1):9-17. doi:10.1016/j.phymed.2015.11.003.

50. Gill BS, Mehra R, Navgeet, Kumar S. Vitex negundo and its medicinal value. Mol Biol Rep. 2018;45(6):2925-2934. doi:10.1007/s11033-018-4421-3.

51. Liou CJ, Len WB, Wu SJ, Lin CF, Wu XL, Huang WC. Casticin inhibits COX-2 and iNOS expression via suppression of NF$\mathrm{\kappa B}$ and MAPK signaling in lipopolysaccharide-stimulated mouse macrophages. J Ethnopharmacol. 2014;158 Pt A:310316. doi:10.1016/j.jep.2014.10.046.

52. Adhikarya R, Majhia A, Mahantia S, Bishayia B. Immunomodulatory and anti-oxidant properties of methanolic extract of Adhatoda vasica Nees leaf after particulate antigen stimulation in mice. J Pharm Res. 2014;8(10):1520-1537.

53. Cheng L, Zheng W, Li M, et al. Citrus Fruits Are Rich in Flavonoids for Immunoregulation and Potential Targeting ACE2. Preprints; 2020.

54. Sultan MT, Butt MS, Qayyum MM, Suleria HA. Immunity: plants as effective mediators. Crit Rev Food Sci Nutr. 2014;54(10):1298-1308. doi:10.1080/10408398.2011.63324 9.

55. Nugraha RV, Ridwansyah H, Ghozali M, Khairani AF, Atik N. Traditional herbal medicine candidates as complementary treatments for COVID-19: A Review of Their Mechanisms, Pros and Cons. Evid Based Complement Alternat Med. 2020;2020:2560645. doi:10.1155/2020/2560645. 